\title{
ON THE COLLAGEN MINERALIZATION. A REVIEW
}

\author{
GHEORGHE TOMOAIA ${ }^{1}$, ROXANA-DIANA PASCA ${ }^{1,2}$
}

\author{
${ }^{1}$ Orthopedic Department, Iuliu Hatieganu University of Medicine and Pharmacy, \\ Cluj-Napoca, Romania \\ ${ }^{2}$ Chemical Engineering Department, Babes-Bolyai University of Cluj-Napoca, \\ Romania
}

\begin{abstract}
Collagen mineralization (CM) is a challenging process that has received a lot of attention in the past years. Among the reasons for this interest, the key role is the importance of collagen and hydroxyapatite in natural bone, as major constituents. Different protocols of mineralization have been developed, specially using simulated body fluid $(S B F)$ and many methods have been used to characterize the systems obtained, starting with methods of determining the mineral content (XRD, FTIR, Raman, High-Resolution Spectral Ultrasound Imaging), continuing with imaging methods (AFM, TEM, SEM, Fluorescence Microscopy), thermal analysis (DSC and TGA), evaluation of the mechanical and biological properties, including statistical methods and molecular modeling. In spite of the great number of studies regarding collagen mineralization, its mechanism, both in vivo and in vitro, is not completely understood. Some of the methods used in vitro and investigation methods are reviewed here.
\end{abstract}

Keywords: bone, collagen, hydroxyapatite, mineralization, scaffold, biomaterial.

\section{Introduction}

Research on in vitro mineralization of self assembled collagen fibrils is a largely approached dynamic domain, since there is great interest in bone grafts based on this kind of composite materials.

The name bone designates a family of natural materials, nanocomposites presenting a multi-level complex hierarchical structure based on mineralized collagen fibrils [1-2].

Collagen is a complex protein having a repetitive sequence of amino-acids, in particular: glycine, proline and hydroxyproline (Fig. 1). More than 20 types of collagen have been identified until now, but collagen type I and collagen III are the most abundant in nature [3-6]. Collagen can be found in different parts of the human body, such as: cornea, skin, tendon, cartilage, and bone [7]. Collagen type $\mathrm{I}$ is the most abundant protein in the natural bone [8-9].

Bone is one of the most perfect natural structures

Manuscript received: 15.10 .2014

Accepted: 17.12.2014

Address for correspondence: roxana_diana_pasca@yahoo.com<smiles>O=C(O)C1CCCN1</smiles><smiles>NNCC(=O)O</smiles>

Figure 1. Chemical structures of the collagen main constituents: proline, hydroxyproline and glycine.

[10] and its reconstruction has great importance in treating different orthopedic diseases including cancer. Bone is the main structure to support the body and protect internal organs in vertebrates $[1,11]$, and also it is important in maintaining the concentration of inorganic ions $\left(\mathrm{Ca}^{2+}, \mathrm{PO}_{4}^{3-}\right.$ ) through continuous resorption and remodeling $[2,12]$.

In bone, mineralized collagen usually contains calcium phosphate based crystals, having as principal components $\mathrm{Ca}^{2+}$ and $\mathrm{PO}_{4}^{3-}$ (phosphate) ions, but also small amounts of other cations, such as $\mathrm{Mg}^{2+}$, and anions: $\mathrm{CO}_{3}{ }^{2-}$ (carbonate), $\mathrm{OH}^{-}$(hydroxyl), $\mathrm{Cl}^{-}$(chloride), $\mathrm{F}^{-}$(fluoride), citrate and other [13]. These calcium phosphate phases 
implied in the mineralization of collagen fibrils are similar to hydroxyapatite (HAP) [14].

Bone contains, in principal, 3 types of components, namely: inorganic materials $(65-70 \%$, especially hydroxyapatite, HAP, which confers hardness), organic mass $(20-25 \%)$ : collagen type I, predominantly, which offers the elasticity necessary for movement and small quantities of osteonectin and osteoclacin that lead to the regeneration of the bone), and water associated with collagen $(10 \%)[12,15]$.

But composition alone does not account for the outstanding mechanical properties (strength and toughness) of bone, which are essentially determined by its nanostructure, organized on seven levels of hierarchy $[1,16$ 17]. In all bone materials, there is the same basic building block: a collagen fibril, with HAP crystals (platelets), with their c-axes $\left[\begin{array}{lll}0 & 0 & 1\end{array}\right]$ aligned preferentially parallel to long axis of the fibril. These fibrils were beforehand arranged by self assembly in a matrix presenting a periodic array of hole and overlap zones [17]. HAP crystals probably nucleate in the hole zones, but outgrow them and are stored between tropo-collagen molecules (triple helices of collagen peptides), thus generating an interpenetrating organicinorganic nanocomposite [18]. Due to the metastability of the extremely small HAP nanocrystals, they can be resorbed by osteoclasts during the natural remodeling processes of the bone [19]. Afterwards these mineralized fibrils selfassemble further into higher levels of structure, for instance in parallel arrays that rotate across the concentric lamellae of osteons [1,20] with further hierarchy directed by osteoblasts as they lay down a trabecular and cortical bone macrostructure [12]. As a particular case, mature enamel - the hardest tissue in the body - contains 95\% apatitic mineral, $4 \%$ water and less than $1 \%$ of organic matrix [16].

In the natural bone, mineralization of collagen is the result of complex biological processes ssee, for example [7,21-22]\} in which deposition of inorganic salts is induced by a template of collagen network formed through self-assembly [23]. It was -intensively studied over the last 50 years, but the exact molecular mechanism of mineralization of bone collagen is not completely elucidated till now [23-24]. Since type I collagen by itself cannot induce apatite nucleation [25], non-collagenous proteins such as osteonectin and osteocalcin [26] contribute to the stabilization of amorphous calcium phosphate phases as nanoprecursors (sequestration motif) [27-28], and to the initiation of nucleation and hierarchical assembly of apatite within the collagen scaffold (templating motif) [29]. The present review will present only in vitro methods for collagen mineralization.

\section{Different ways of preparing mineralized collagen}

At present there is an increasing demand for improved bone graft substitutes in order to mimic the properties of natural bone, a great number of organic/ inorganic composites have been proposed.

Three-dimensional scaffolds are used in tissue engineering for cell cultures, to form a mature matrix for implantation into the body [30]. The scaffold is the initial support for the cells, and it has an important effect on cell processes (proliferation, migration, etc) [31]. It must have a series of characteristics such as: high porosity, mechanical stability, biocompatibility and biodegradability [15]. Mostly collagen and hydroxyapatite have been considered as scaffold materials for bone tissue culture for regeneration.

As shown above, fibrous type I collagen is chemically and structurally similar to natural extracellular matrices [33], and it is combined in bone with (carbonated) hydroxyapatite in a hierarchically organized biocomposite tissue, from nano to macroscopic scale [1]. It is commonly used as a biomaterial in scaffolds, due to its stability, bioactivity and biocompatibility. Collagen gels support cellular proliferation and osteogenic differentiation in a three-dimensional matrix [34]. Bovine tissues are the main commercial source of collagen, but also other sources were considered, especially after Bovine Spongiform Encephalopathy became a major concern. For instance, collagen-rich fish solid waste was taken in consideration as an alternative source [35].

Simple collagen scaffolds and constructs could be used in bone implants without mineralization, but they would need more then 2-3 weeks for osteointegration [36]. This is why as a rule composites of collagen and HAP are used [37], but also other inorganic materials were considered, such as silica. The mineralization process improves the mechanical resistance of collagen and makes it a suitable matrix for bone repair [38].

Such mineralized matrices are a valuable biomedical tool for regulating diverse phenotypic activities of stem and progenitor cells in the repair and regeneration of bone tissues [39-40], but are also useful in the study of bone diseases, e.g. osteoporosis or cancer metastasis [41].

Early bone grafts used to be based on highly crystalline sintered HAP, but this material is not readily resorbed by the body, so now research is focused on composites based on amorphous HAP [10].

Among the methods of preparing mineralized collagen, we can distinguish $[12,15]$ :

- the direct blending of collagen and mineral crystals, i.e. simply mixing together collagen and mineral nanoparticles;

- the co-precipitation of mineral during collagen fibrillogenesis;

- the "biomimetic" approach of immersion of collagen scaffolds in simulated body fluid, SBF [7] to coat the collagen scaffold surfaces with minerals.

SBF is also used for the direct surface modification of metallic and other implants The classical Kokubo 
solution formulated with ion concentrations similar to blood plasma [42] has the following ionic composition $(\mathrm{mmol} / \mathrm{L}): \mathrm{Na}^{+} 142.0 ; \mathrm{K}^{+} 5.0 ; \mathrm{Mg}^{2+} 1.5 ; \mathrm{Ca}^{2+} 2.5 ; \mathrm{Cl}^{-}$ 147.8; $\mathrm{HCO}_{3}^{-} 4.2 ; \mathrm{HPO}_{4}^{2-} 1.0 ; \mathrm{SO}_{4}{ }^{2-} 0.5$. As a precursor for the collagen mineralization, it is prepared by mixing in ultrapure water the following solutions: $\mathrm{NaCl}, \mathrm{NaHCO}_{3}$, $\mathrm{KCl}, \mathrm{K}_{2} \mathrm{HPO}_{4} \cdot 3 \mathrm{H}_{2} \mathrm{O}, \mathrm{MgCl}_{2} \cdot 6 \mathrm{H}_{2} \mathrm{O}, \mathrm{CaCl}_{2}$, and $\mathrm{Na}_{2} \mathrm{SO} 4$, adjusted to physiological $\mathrm{pH}$ (7.4) [23].

The enrichment of SBF with transition metal ions was also proposed [23]. Ions of this kind $\left(\mathrm{Co}^{2+}, \mathrm{Ni}^{2+}, \mathrm{Zn}^{2+}\right.$ $\left., \mathrm{Fe}^{3+}, \mathrm{Mn}^{2+}, \mathrm{Cu}^{2+}\right)$ used to dope HAP, play an important role as trace elements for the growth and metabolism of bone tissues, in preventing and treating bone diseases.

The co-precipitation method to obtain collagen/ calcium phosphate composites implies the self assembly of collagen fibrils from soluble molecules and the precipitation of calcium phosphate (mostly HAP) in aqueous solution [43-45]. For instance, a basic solution containing $\mathrm{Ca}^{2+}$ was added drop-wise to a solution containing dissolved type I collagen in phosphoric acid. The self assembly of collagen takes place simultaneously with the precipitation of HAP at $\mathrm{pH} 9-10$, giving their nanocomposite $[44,46]$. Instead of collagen, gelatin - its denaturated form - was also used [47]. Such materials present a rather good bioactivity, but have poor mechanical properties, which limit their applications [48].

The most commonly used surface mineralization techniques [10] include soaking the scaffold in (SBF) [4950] and the alternating dipping method [51], the last being faster (hours instead of days duration). But it is difficult for the solution to reach the interior of the nanofibrous block. An in situ diffusion method [52] tries to obtain collagen/nanoHAP scaffolds with a concentration gradient, from solutions containing $\mathrm{Ca}^{2+}$ and $\mathrm{PO}_{4}^{3-}$ ions, which precipitate HAP crystallites on the collagen fibrils. In order to control the ionic diffusion during the mineralization process, a dual membrane diffusion system was proposed, with a cation-selective membrane and an anion-selective dialysis membrane and a carboxymethylated collagen fibril substrate [53].

Mineralization of scaffolds induced by incubating collagen matrices in SBF or by activation of calcium and phosphate secretion from cells loaded within the matrix [54] improves the bonding of the implants to the bone and the osteogenic differentiation of bone-forming stem and progenitor cells [40]. But such collagen gels encapsulating calcium-secreting cells lack rigidity and tend to shrink significantly. [40, 55].

Such conventional in vitro collagen mineralization methods, realized by the nucleation and growth technique, using a direct combination of reactant ions and/or various forms of simulated body fluid as the reaction media [56-60] cannot reproduce the native nanostructure of bone which arises from intrafibrillar mineralization. HAP crystals appear randomly oriented in spheritic clusters on the surface of the collagen scaffolds [17]. It is possible that the external mineral crust formed prevents further mineralization of the collagen fibrils beneath the surface [17,61].

Since these collagen-calcium phosphate composites have inadequate mechanical properties, in order to improve these characteristics synthetic polymers or agents for crosslinking are added. Among the polymers used to strengthen the mineralized collagen we can cite poly (lactic acid (PLA) [62] or the copolymer poly(lactic-co-glycolic acid) (PLGA) [40]. Some cross-linking agents used are glutaraldehyde [63-64], succinic anhydride, and acyl azide [65], 3-Aminopropyl triethoxysilane [36]. A disadvantage of these agents is their cytotoxic properties.

Of course, there is also the possibility to apply collagen/ calcium phosphate composite coatings on the surface of metallic implants; so we obtain a bioactive surface together with the high mechanical characteristics of the metal core [66]. To this aim, the use of electrolysis proved to be useful for collagen self-assembly and calcium phosphate mineralization [48]. Electrochemical processes are also implied in the electro-deposition of hydroxyapatite on collagen [67], or in the electrochemically assisted deposition of coatings from a $\mathrm{Ca}^{2+} / \mathrm{H}_{\mathrm{x}} \mathrm{PO}_{4}{ }^{(3-x)}$ electrolyte at physiological $\mathrm{pH}$ and temperature [68].

The methods using SBF are often named "biomimetic", but as a matter of fact, they do not accurately mimic the in vivo bone formation process, particularly intrafibrillar mineralization, and often result in scaffolds that are not suitable for bone tissue engineering.

A fundamental breakthrough in mimicking intrafibrillar mineralization was reached by the method of the polymer-induced liquid precursor (PILP) process [6970]. The addition of acidic polypeptides to the mineralization solution induces or stabilizes an amorphous highly hydrated precursor to the mineral (HAP), with a liquid-like character. This process could even explain the biological biomineral morphogenesis in vertebrates and invertebrates [71]. By this process, intrafibrillar mineralization of collagen can be realized in vitro: the HAP nanocrystals are embedded and [0 0 1] aligned within collagen fibrils, as in the nanostructure of natural bone [71-73]. The acidic polypeptides mimick the role of the noncollagenous proteins such as osteonectin and osteocalcin in the natural process, and permit intrafibrillar mineralization [71,74-77].

The mineralization by the PILP process of individual collagen fibrils were studied and the products were characterized $[71,75,77]$. The randomly oriented bundles of fibrils in the form of porous collagen scaffolds were also investigated [17,71,77,78-79].

In one of the approaches, polyaspartate was used to mimic the acidic non-collagenous proteins involved in bone formation, and alkaline phosphatase to provide a slow release of inorganic phosphate ions from a phosphate ester [17]. Polyaspartic acid, together with $\mathrm{K}_{2} \mathrm{HPO}_{4}$ and $\mathrm{CaCl}_{2}$ were used in a perfusion-flow (dynamic) mineralization 
technique, to obtain a collagen-HAP composite with structure and compositions similar to human trabecular bone [15]. Recently, osteopontin was used in such a process, and was shown to modulate both the mineralization reaction, and the cellular activity [80]. Polyacrylic acid was also used as sequestration analogue (to stabilize amorphous calcium phosphate into nanoprecursors) along with poly vinyl phosphoric acid (as substitute for matrix phosphoproteins), as templating analogue (to direct the nucleation and growth of apatite within collagen fibrils) for the remineralization in SBF of dentine collagen [21]. Small inorganic poly-phosphates (sodium trimetaphosphate and sodium tripolyphosphate) could also be used as templating analogues [22]. The role of phosphoproteins in the mineralization process was discussed [81].

Besides calcium phosphates, silica was used as an alternative in the mineralization of collagen, both because of the mechanical properties of the resulted innovative biomaterial, and for the stimulating effect of silicic acid in osteogenesis [82]. Composite from collagen and bioglass particles were prepared [33,83-84]. The same mineralization methods were used as for phosphates: silicification of previously assembled collagen fibrils [85], or simultaneous collagen fibrillogenesis and silica polymerization [86]. A silica/collagen/hydroxyapatite composite biomaterial was also obtained $[14,87]$. The modern method of intrafibrillar mineralization used for calcium phosphates was extended to biosilification [38].

\section{Characterization of the mineralized collagen}

The principal methods used to characterize the mineralized collagen are summarized in Table I, along with a few references to their application. All of them can offer important views on the collagen behavior under the mineralization process and further perspectives on the mechanism involved.

The characterization of the mineralized collagen can be accomplished by using various techniques, most of the studies are using microscopy (SEM, TEM, AFM and fluorescence) to visualize the mineralized collagen fiber or spectroscopy (X-ray, FTIR, Raman, High-Resolution Spectral Ultrasound Imaging) to determine the chemical content of the samples and in vitro tests on cell cultures to see the interaction of the new material with the biological medium, but some other methods such as: determining the mechanical properties of the probes, analyzing the thermal behavior (DSC, TGA), or the absorption capacity and some molecular simulations of the interactions that may occur between collagen and the other components (specially hydroxyapatite) are mentioned.

\section{Conclusions}

Mineralizing the collagen is not an easy task; it can be accomplished under specific conditions and it depends on many parameters involved. A glimpse on the methods used to this aim evidences a continuous trend toward the development of biomimetic methods, in order to approach in vitro the natural processes of osteogenesis and to obtain materials presenting characteristics near to the ideal of natural bone. The degree of success can be estimated using a large variety of up to date investigation techniques and data processing methods.

\section{Acknowledgments}

Dr. Roxana-Diana Pasca acknowledges financial support from a POSDRU grant, no. 159/1.5/S/138776, grant with the title: "Model colaborativ institutional pentru translatarea cercetarii stiintifice biomedicale in practica

Table I. Methods of characterization for mineralized collagen.

\begin{tabular}{|c|c|}
\hline Method & Reference \\
\hline \multicolumn{2}{|l|}{ Morphological characterization: } \\
\hline Scanning Electron Microscopy (SEM) & {$[12,15,23,33,36,40,48,53,68,78,80,88-96]$} \\
\hline Transmission Electron Microscopy (TEM) & {$[12,16,21-22,24,48,53,78,89,95,97-100]$} \\
\hline Atomic Force Microscopy (AFM) & {$[68,96,98]$} \\
\hline Fluorescence Microscopy & {$[33,53,101]$} \\
\hline \multicolumn{2}{|l|}{ Mineral content: } \\
\hline X-ray Diffraction (XRD) & {$[12,15,23,33,36,40,74,80,88-90,93,95,102-103]$} \\
\hline Fourier transform infrared spectroscopy (FTIR) & {$[21-23,33,36,48,68,87,89,91,94-95,97,102,105]$} \\
\hline Raman Spectroscopy & {$[33,74]$} \\
\hline High-Resolution Spectral Ultrasound Imaging & {$[55]$} \\
\hline \multicolumn{2}{|l|}{ Mechanical properties: } \\
\hline Modulus of elasticity & {$[15,33]$} \\
\hline \multicolumn{2}{|l|}{ Biocompatibility: } \\
\hline Cell culture & {$[15,33,35,50,80,95,97,100,102,106-116]$} \\
\hline \multicolumn{2}{|l|}{ Thermal analysis: } \\
\hline Differential Scanning Calorimetry (DSC) & {$[36]$} \\
\hline Thermogravimetric Analysis (TGA) & {$[12,80]$} \\
\hline Adsorption isotherms: & {$[21]$} \\
\hline Molecular modeling: & {$[117,118]$} \\
\hline
\end{tabular}


clinica- TRANSCENT".

\section{References:}

1. Weiner S, Wagner HD. The material bone: structure-mechanical function relations. Annu Rev Mater Res. 1998;28:271-298.

2. Weiner S, Traub W, Wagner HD. Lamellar bone: structurefunction relations. J Struct Biol. 1999;126:241-256.

3. Saito M, Marumo K. Collagen cross-links as a determinant of bone quality: a possible explanation for bone fragility in aging, osteoporosis, and diabetes mellitus. Osteoporos Int. 2010;21:195214.

4. Dominguez LJ, Barbagallo M, Moro L. Collagen overglycosylation: A biochemical feature that may contribute to bone quality. Biochem Bioph Res Commun. 2005;330:1-4.

5. Matsuura T, Tokutomi K, Sasaki M, Katafuchi M, Mizumachi E, Sato H. Distinct Characteristics of Mandibular Bone Collagen Relative to Long Bone Collagen: Relevance to Clinical Dentistry. Biomed Res Int 2014;769414:1-9.

6. Leeming DJ, Henriksen K, Byrjalsen I, Qvist P, Madsen SH, Garnero P, et al. Is bone quality associated with collagen age? Osteoporos Int. 2009;20:1461-1470.

7. Cui FZ, Li Y, Ge J. Self-assembly of mineralized collagen composites. Mater Sci Eng R. 2007; 57:1-27.

8. D’Ulivo L, Witos J, Oorni K, Kovanen PT, Riekkola ML. CEC: A tool for mimicking collagen-surface interactions with apolipoprotein B-100 peptides. Electrophoresis 2009; 30:38383845.

9. Stoller P, Reiser KM, Celliers PM, Rubenchik AM. Polarizationmodulated second harmonic generation in collagen. Biophys $\mathrm{J}$. 2002;82:3330-3342.

10. Teo WE, Liao S, Chan C, Ramakrishna S. Fabrication and characterization of hierarchically organized nanoparticlereinforced nanofibrous composite scaffolds. Acta Biomater. 2011;7:193-202.

11. Currey JD. The design of mineralized hard tissues for their mechanical functions. J Exp Biol. 1999;202:3285-3294.

12. Thula TT, Rodriguez DE, Lee DE, Pendi L, Podschun J, Gower LB. In vitro mineralization of dense collagen substrates: A biomimetic approach toward the development of bone-graft materials. Acta Biomater. 2011;7:3158-3169.

13. de Groot K. Effect of Porosity and Physicochemical Properties on the Stability, Resorption, and Strength of Calcium Phosphate Ceramics. Ann NY Acad Sci. 1988;523:227-233.

14. Heinemann S, Coradin T, Worch H, Wiesmann HP, Hanke T. Possibilities and limitations of preparing silica/collagen/ hydroxyapatite composite xerogels as load-bearing biomaterials. Compos Sci Technol. 2011;71:1873-1880.

15. Antebi B, Cheng X, Harris JN, Gower LB, Chen XD, Ling J. Biomimetic collagen-hydroxyapatite composite fabricated via a novel perfusion-flow mineralization technique. Tissue Eng. 2013;19:487-496.

16. Deshpande AS, Fang PA, Simmer JP, Margolis HC, Beniash E. Amelogenin-collagen interactions regulate calcium phosphate mineralization in vitro. J Biol Chem. 2010;285:19277-19287.

17. Jee SS, Culver L, Li Y, Douglas EP, Gower LB. Biomimetic mineralization of collagen via an enzyme-aided PILP process. J Cryst Growth. 2010;312:1249-1256.

18. Traub W, Arad T, Weiner S. Three-dimensional ordered distribution of crystals in turkey tendon collagen fibers. Proc Natl Acad Sci U S A. 1989;86:9822-9826.

19. Gower LB. Biomimetic model systems for investigating the amorphous precursor pathway and its role in biomineralization. Chem Rev. 2008;108:4551-4627.

20. Wagermaier W, Gupta HS, Gourrier A, Burghammer M, Roschger P, Fratzl P. Spiral twisting of fiber orientation inside bone lamellae. Biointerphases. 2006;1:1-5.

21. Gu LS, Kim YK, Liu Y, et al. Immobilization of a phosphonated analog of matrix phosphoproteins within cross-linked collagen as a templating mechanism for biomimetic mineralization. Acta Biomater. 2011;7:268-277.

22. Meyers MA, Chen PY, Lin AYM, Seki Y. Biological materials: Structure and mechanical properties. Progr Mater Sci. 2008;53:1206.

23. Jia M, Hong Y, Duan S, Liu Y, Yuan B, Jiang F. The influence of transition metal ions on collagen mineralization. Mat Sci Eng C Mater Biol Appl. 2013;33:2399-2406.

24. Eyre DR, Weis MA. Bone collagen: new clues to its mineralization mechanism from recessive osteogenesis imperfecta. Calcif Tissue Int. 2013; 93:338-347.

25. Glimcher MJ. Mechanism of calcification: role of collagen fibrils and collagenphosphoprotein complexes in vitro and in vivo. Anat Rec. 1989; 224:139-153.

26. Clarke B. Normal bone anatomy and physiology. Clin J Am Soc Nephrol. 2008; 3 Suppl 3:S131-S139.

27. Tao J, Pan H, Zeng Y, Xu X, Tang R. Roles of amorphous calcium phosphate and biological additives in the assembly of hydroxyapatite nanoparticles. J Phys Chem B. 2007;111:1341013418.

28. Veis A. The role of acidic proteins in biological mineralization. In: Everett H, Vincent $\mathrm{G}$ (eds) Ions in macromolecular and biological systems. Bristol, United Kingdom: Scientechnia; 1978, 259-267.

29. Weiner S. Biomineralization: a structural perspective. J Struct Biol. 2008;163:229-234.

30. Persidis A. Tissue engineering. Nat Biotechnol. 1999;17:508510 .

31. Hollister SJ. Porous scaffold design for tissue engineering. Nat Mater. 2005;4:518-524.

32. Ma PX. Scaffolds for tissue fabrication. Mater Today. 2004;7:30-40.

33. Marelli B, Ghezzi CE, Mohn D, Stark WJ, Barralet JE, Boccaccini AR, et al. Accelerated mineralization of dense collagen-nano bioactive glass hybrid gels increases scaffold stiffness and regulates osteoblastic function. Biomaterials. 2011;32:8915-8926.

34. Donzelli E, Salvade A, Mimo P, Viganò M, Morrone M, Papagna R, et al. Mesenchymal stem cells cultured on a collagen scaffold: in vitro osteogenic differentiation. Arch Oral Biol. 2007;52:64-73.

35. Yamada S, Nagaoka H, Terajima M, Tsuda N, Hayashi Y, Yamauchi M. Effects of fish collagen peptides on collagen posttranslational modifications and mineralization in an osteoblastic cell culture system. Dent Mater J. 2013;32:88-95.

36. Raghavan RN, Muthukumar T, Somanathan N, Sastry TP. Biomimetic mineralization of novel silane crosslinked collagen. Mater Sci Eng C Mater Biol Appl. 2013;33:1983-1988.

37. Wahl DA, Czernuska JT. Collagen-hydroxyapatite composites for hard tissue repair. Eur Cell Mater. 2006; 11:43-56.

38. Niu L, Jiao K, Qi Y, Yiu CK, Ryou H, Arola DD, et al. Infiltration of Silica Inside Fibrillar Collagen. Angew Chem Int Ed Engl. 2011;50:11688-11691.

39. Salgado AJ, Coutinho OP, Reis RL. Bone tissue engineering: 
state of the art and future trends. Macromol Biosci. 2004;4:743765 .

40. DeVolder RJ, Kim IW, Kim ES, Kong H. Modulating the rigidity and mineralization of collagen gels using poly (lactic-coglycolic acid) microparticles. Tissue Eng Part A. 2012;18:16421651.

41. Pathi SP, Lin DDW, Dorvee JR, Estroff LA, Fischbach C. Hydroxyapatite nanoparticle-containing scaffolds for the study of breast cancer bone metastasis. Biomaterials. 2011;32:5112-5122. 42. Kokubo T, Kushitani H, Sakka S, Kitsugi T, Yamamuro T. Solutions able to reproduce in vivo surface-structure changes in bioactive glass-ceramic A-W. J Biomed Mater Res. 1990;24:721734.

43. Bradt JH, Mertig M, Teresiak A, Pompe W. Biomimetic mineralization of collagen by combined fibril assembly and calcium phosphate formation. Chem Mater. 1999;1:2694-2701.

44. Kikuchi M, Itoh S, Ichinose S, Shinomiya K, Tanaka J. Selforganization mechanism in a bone-like hydroxyapatite/collagen nanocomposite synthesized in vitro and its biological reaction in vivo. Biomaterials. 2001;22:1705-1711.

45. Tampieri A, Celotti G, Landi E, Sandri M, Roveri N, Falini G. Biologically inspired synthesis of bone-like composite: self-assembled collagen fibers/hydroxyapatite nanocrystals. J Biomater Mater Res A. 2003;67:618-625.

46. Du C, Cui FZ, Zhang W, Feng QL, Zhu XD, de Groot K. Formation of calcium phosphate/collagen composites through mineralization of collagen matrix. J Biomed Mater Res. 2000;50:518-527.

47. Chang MC, Ko CC, Douglas WH. Preparation of hydroxyapatite-gelatin nanocomposite. Biomaterials. 2003;24:2853-2862.

48. Fan Y, Duan K, Wang R. A composite coating by electrolysisinduced collagen self-assembly and calcium phosphate mineralization. Biomaterials. 2005;26:1623-1632.

49. Wei G, Ma P. Macroporous and nanofibrous polymer scaffolds and polymer/bone-like apatite composite scaffolds generated by sugar spheres. J Biomed Mater Res A. 2006;78A:306-301.

50. Rao RR, Jiao A, Kohn DH, Stegemann JP. Exogenous mineralization of cell-seeded and unseeded collagen-chitosan hydrogels using modified culture medium. Acta Biomater. 2012;8:1560-1565.

51. Ngiam M, Liao S, Patil A, Cheng Z, Yang F, Gubler MJ, et al. Fabrication of mineralized polymeric nanofibrous composites for bone graft materials. Tissue Eng Part A. 2009;15:535-546.

52. Liu C, Han Z, Czernuszk JT. Gradient collagen/ nanohydroxyapatite composite scaffold: Development and characterization. Acta Biomater. 2009;5:661-669.

53. Ehrlich H, Hanke T, Born R, Fischer C, Frolov A, Langrock $\mathrm{T}$, et al. Mineralization of biomimetically carboxymethylated collagen fibrils in a model dual membrane diffusion system. J Membr Sci. 2009; 326:254-259.

54. Matsumoto T, Okazaki M, Sasaki J, Hamada Y, Takahashi J. Role of acidic amino acid for regulating hydroxyapatite crystal growth. Dent Mater J. 2006;25:360-364.

55. Gudur M, Rao RR, Hsiao YS, Peterson AW, Deng CX, Stegemann JP. Noninvasive, quantitative, spatiotemporal characterization of mineralization in three-dimensional collagen hydrogels using high-resolution spectral ultrasound imaging. Tissue Eng Part C Methods. 2012;18:935-946.

56. Rhee SH, Tanaka J. Hydroxyapatite coating on a collagen membrane by a biomimetic method. J Am Ceram Soc. 1998;
81:3029-3031.

57. Rhee SH, Lee JD, Tanaka J. Nucleation of hydroxyapatite crystal through chemical interaction with collagen. J Am Ceram Soc. 2000;83:2890-2892.

58. Lickorish D, Ramshaw JAM, Werkmeister JA, Glattauer V, Howlett CR. Collagen-hydroxyapatite composite prepared by biomimetic process. J Biomed Mater Res A. 2004;68:19-27.

59. Liao S, Watari F, Uo M, Ohkawa S, Tamura K, Wang W, et al. The preparation and characteristics of a carbonated hydroxyapatite/ collagen composite at room temperature. J Biomed Mater Res B Appl Biomater. 2005;74:817-821.

60. Zhai Y, Cui FZ, Wang Y. Formation of nano-hydroxyapatite on recombinant human-like collagen fibrils. Curr Appl Phys. 2005;5:429-432.

61. Doi Y, Horiguchi T, Moriwaki Y, Kitago H, Kajimoto T, Iwayama Y. Formation of apatite-collagen complexes. J Biomed Mater Res. 1996;31:43-49.

62. Liao SS, Guan K, Cui FZ, Shi SS, Sun TS. Lumbar spinal fusion with a mineralized collagen matrix and rhBMP-2 in a rabbit model. Spine (Phila Pa 1976). 2003;28:1954-1960.

63. Chang MC, Tanaka J. FT-IR study for hydroxyapa tite/collagen nanocomposite cross-linked by glutaraldehyde. Biomaterials. 2002;23:4811-4818.

64. Kikuchi M, Matsumoto HN, Yamada T, Koyama Y, Takakuda K, Tanaka J. Glutaraldehyde cross-linked hydroxyapatite/collagen self-organized nanocomposites. Biomaterials. 2004;25:63-69.

65. Lee KY, Mooney D.J. Hydrogels for tissue engineering. Chem Rev. 2001;101:1869-1879.

66. Schliephake H, Scharnweber D, Dard M, Rossler S, Sewing A, Huttmann C. Biological performance of biomimetic calcium phosphate coating of titanium implants in the dog mandible. $\mathrm{J}$ Biomed Mater Res A. 2003;64:225-234.

67. Manara S, Paolucci F, Palazzo B, Marcaccio M, Foresti E, Tosi G, et al. Electrochemically-assisted deposition of biomimetic hydroxyapatite-collagen coatings on titanium plate. Inorg Chim Acta. 2008;361:1634-1645.

68 Tejero R, Bierbaum S, Douglas T, Reinstorf A, Worch H, Scharnweber D. Glucuronic acid and phosphoserine act as mineralization mediators of collagen I based biomimetic substrates. J Mater Sci Mater Med. 2010;21:407-418.

69. Gower LB, Odom DJ. Deposition of calcium carbonate films by a polymer-induced liquid-precursor (PILP) process. J Cryst Growth. 2000;210:719-734.

70. Dai L, Douglas EP, Gower EP. Compositional analysis of a polymer-induced liquid-precursor (PILP) amorphous $\mathrm{CaCO} 3$ phase. J Non-Cryst Solids. 2008; 354:1845-1854.

71. Olszta MJ, Cheng X, Jee SS, Kumar R, Kim Y-Y, Kaufman $\mathrm{MJ}$, et al. Bone structure and formation: a new perspective. Mater Sci Eng R. 2007;58:77-116.

72. Olszta MJ, Douglas EP, Gower LB. Scanning electron microscopic analysis of the mineralization of type I collagen via a polymer-induced liquid-precursor (PILP) process. Calcif Tissue Int. 2003;72:583-591.

73. Olszta MJ, Odom DJ, Douglas EP, Gower LB. A new paradigm for biomineral formation: mineralization via an amorphous liquidphase precursor, Connect Tissue Res. 2003;44:326-334.

74. Chen J, Burger C, Krishnan CV, Chu B, Hsiao BS, Glimcher MJ. In vitro mineralization of collagen in demineralized fish bone. Macromol Chem Phys. 2005;206:43-51.

75. Deshpande AS, Beniash E. Bioinspired synthesis of mineralized collagen fibrils. Cryst Growth Des. 2008;8:3084- 
3090.

76. Liu Y, Kim YK, Dai L, Li N, Khan SO, Pashley DH, et al. Hierarchical and non-hierarchical mineralisation of collagen. Biomaterials. 2011; 32:1291-1300.

77. Nudelman F, Pieterse K, George A, Bomans PH, Friedrich H, Brylka LJ, Hilbers PA, et al. The role of collagen in bone apatite formation in the presence of hydroxyapatite nucleation inhibitors. Nat Mater. 2010;9:1004-1009.

78. Jee SS, Thula TT, Gower LB. Development of bone-like composites via the polymer-induced liquid-precursor (PILP) process. Part 1: influence of polymer molecular weight. Acta Biomater. 2010;6:3676-3686.

79. Thula TT, Svedlund F, Rodriguez DE, Podschun J, Pendi L, Gower LB, Mimicking the nanostructure of bone: comparison of polymeric process-directing agents. Polymers (Basel). 2011;3:10 35 .

80. Rodriguez DE, Thula-Mata T, Toro EJ, Yeh YW, Holt C, Holliday LS, et al. Multifunctional role of osteopontin in directing intrafibrillar mineralization of collagen and activation of osteoclasts. Acta Biomater. 2014; 10:494-507.

81. Yang C, Wang Y, Chen X. Mineralization regulation and biological influence of bioactive glass-collagen-phosphatidylserine composite scaffolds. Sci China Life Sci. 2012;55:236-240.

82. Hoppe A, Güldal N, Boccaccini AR. A review of the biological response to ionic dissolution products from bioactive glasses and glass-ceramics. Biomaterials. 2011;32:2757-2574.

83. Eglin D, Maalheem S, Livage J, Coradin T. In vitro apatite forming ability of type I collagen hydrogels containing bioactive glass and silica sol-gel particles. J Mater Sci Mater Med. 2006; 17:161-167;

84. Marelli B, Ghezzi CE, Barralet JE, Boccaccini AR, Nazhat SN. Three-dimensional mineralization of dense nanofibrillar collagenbioglass hybrid scaffolds. Biomacromolecules. 2010;11:1470 1479.

85. Heinemann S, Heinemann C, Ehrlich H, Meyer M, Baltzer $\mathrm{H}$, Worch $\mathrm{H}$, et al. A novel biomimetic hybrid material made of silicified collagen: perspectives for bone replacement. Adv Eng Mater 2007;9:1061-1068.

86. Desimone MF, Helary C, Mosser G, Giraud-Guille MM, Livage J, Coradin T. Fibroblast encapsulation in hybrid silica/ collagen hydrogels. J Mater Chem. 2010;20:666-668.

87. Heinemann S, Heinemann C, Wenisch S, Alt V, Worch H, Hanke T. Calcium phosphate phases integrated in silica/collagen nanocomposite xerogels enhance the bioactivity and ultimately manipulate the osteoblast/osteoclast ratio in a human co-culture model. Acta Biomater. 2013;9:4878-4888.

88. Falini G, Fermani S, Palazzo B, Roveri N. Helical domain collagen substrates mineralization in simulated body fluid. J Biomed Mater Res A. 2007;87:470-476.

89 Kim YK, Gu LS, Bryan TE, Kim JR, Chen L, Liu $\mathrm{Y}$, et al. Mineralisation of reconstituted collagen using polyvinylphosphonic acid/ polyacrylic acid templating matrix protein analogues in the presence of calcium, phosphate and hydroxyl ions. Biomaterials. 2010;31:6618-6627.

90. Munisamy S, Vaidyanathan TK, Vaidyanathan J. A bone-like precoating strategy for implants: collagen immobilization and mineralization on pure titanium implant surface. J Oral Implantol. 2008;34:67-75.

91. Wang Y, Cui F, Zhai Y, Wang X, Kong X, Fan D. Investigations of the initial stage of recombinant human-like collagen mineralization. Mater Sci Eng. 2006;26:635-638.
92. Ramasamy JG, Akkus O. Local variations in the micromechanical properties of mouse femur: The involvement of collagen fiber orientation and mineralization. J Biomech. 2007;40:910-918.

93. Chesnick IE, Mason JT, Giuseppetti AA, Eidelman N, Potter K. Magnetic resonance microscopy of collagen mineralization. Biophys J. 2008;95:2017-2026.

94. Price PA, Toroian D, Lim JE. Mineralization by inhibitor exclusion: the calcification of collagen with fetuin. J Biol Chem. 2009;284:17092-17101.

95. Venugopal J, Low S, Choon AT, Sampath Kumar TS, Ramakrishna S. Mineralization of osteoblasts with electrospun collagen/hydroxyapatite nanofibers. J Mater Sci Mater Med. 2008;19:2039-2046.

96. Xu P, Huang J, Cebe P, Kaplan DL. Osteogenesis imperfecta collagen-like peptides: self-assembly and mineralization on surfaces. Biomacromolecules. 2008;9:1551-1557.

97. Mochida Y, Parisuthiman D, Pornprasertsuk-Damrongsri S, Atsawasuwan P, Sricholpech M, Boskey AL, et al. Decorin modulates collagen matrix assembly and mineralization. Matrix Biol. 2009;28:44-52.

98. Ge J, Cui FZ, Wang X, Wang Y. New evidence of surface mineralization of collagen fibrils in wild type zebrafish skeleton by AFM and TEM. Mat Sci Eng C-Bio S. 2007;27:46-50.

99. Goldberg M, Septier D, Oldberg A, Young MF, Ameye LG. Fibromodulin-deficient mice display impaired collagen fibrillogenesis in predentin as well as altered dentin mineralization and enamel formation. J Histochem Cytochem. 2006;54:525-537. 100. Pornprasertsuk S, Duarte WR, Mochida Y, Yamauchi M. Overexpression of lysyl hydroxylase-2b leads to defective collagen fibrillogenesis and matrix mineralization. J Bone Miner Res. 2005;20:81-87.

101. Paietta RC, Burger EL, Ferguson VL. Mineralization and collagen orientation throughout aging at the vertebral endplate in the human lumbar spine. J Struct Biol. 2013;184:310-320.

102. Tomomatsu O, Tachibana A, Yamauchi K, Tanabe T. A film of collagen/calcium phosphate composite prepared by enzymatic mineralization in an aqueous solution. J Ceram Soc Japan. 2008;116:10-13.

103. Genge WBR, Wu LNY, Wuthier RE. Mineralization of annexin-5-containing lipid-calcium-phosphate complexes: modulation by varying lipid composition and incubation with cartilage collagens. J Biol Chem. 2008; 283:9737-9748.

104. Genge BR, Wu LNY, Wuthier RE. Kinetic analysis of mineral formation during in vitro modeling of matrix vesicle mineralization: effect of annexin A5, phosphatidylserine, and type II collagen. Anal Biochem. 2007;367:159-166.

105. Jubeck B, Gohr C, Fahey M, Muth E, Matthews M, Mattson E, et al. Promotion of articular cartilage matrix vesicle mineralization by type I collagen. Arthritis Rheum. 2008;58:2809-2817.

106. Jubeck B, Muth E, Gohr CM, Rosenthal AK. Type II collagen levels correlate with mineralization by articular cartilage vesicles. Arthritis Rheum 2009;60:2741-2746.

107. Ding J, Ghali O, Lencel P, et al. TNF- $\alpha$ and IL-1 $\beta$ inhibit RUNX2 and collagen expression but increase alkaline phosphatase activity and mineralization in human mesenchymal stem cells. Life Sci. 2009;84:499-504.

108. Matsuura T, Tsubaki S, Tsuzuki T, Duarte WR, Yamauchi M, Sato H. Differential gene expression of collagen-binding small leucine-rich proteoglycans and lysyl hydroxylases, during mineralization by MC3T3-E1 cells cultured on titanium implant 
material. Eur J Oral Sci. 2005;113:225-231.

109. Kalamajski S, Aspberg A, Lindblom K, Heinegard D, Oldberg A. Asporin competes with decorin for collagen binding, binds calcium and promotes osteoblast collagen mineralization. Biochem J. 2009;423:53-59.

110. Eslaminejad MB, Mirzadeh H, Nickmahzar A, Mohamadi Y, Mivehchi H. Type I collagen gel in seeding medium improves murine mesencymal stem cell loading onto the scaffold, increases their subsequent proliferation, and enhances culture mineralization. J Biomed Mater Res B Appl Biomater. 2009;90:659-667.

111. Couchourel D., Aubry I, Delalandre A, Lavigne M, MartelPelletier J, Pelletier JP, et al. Altered mineralization of human osteoarthritic osteoblasts is attributable to abnormal type I collagen production. Arthritis Rheum. 2009;60:1438-1450.

112. Roschger P, Fratzl-Zelman N, Misof BM, Glorieux FH, Klaushofer K, Rauch F. Evidence that abnormal high bone mineralization in growing children with osteogenesis imperfecta is not associated with specific collagen mutations. Calcif Tissue Int. 2008;82:263-270.

113. Kihara T, Hirose M, Oshima A, Ohgushi H. Exogenous type I collagen facilitates osteogenic differentiation and acts as a substrate for mineralization of rat marrow mesenchymal stem cells in vitro. Biochem Biophys Res Commun. 2006;341:10291035 .

114. Kang SK, Kim KS, Byun YS, Suh SJ, Jim UH, Kim KH, et al. Effects of Ulmus davidiana planch on mineralization, bone morphogencetic protein-2, alkaline phosphatase, type I collagen and collagenase-1 in bone cells. In Vitro Cell Dev Biol Anim. 2006;42:225-229.

115. Kim HJ, Kirsch T. Collagen/annexin V interactions regulate chondrocyte mineralization. J Biol Chem. 2008;283:1031010317.

116. Tomoaia G, Soritau O, Tomoaia-Cotisel M, Pop LB, Pop A, Mocanu A, et al. Scaffolds made of nanostructured phosphates, collagen and chitosan for cell culture. Powder Technol. 2013;238:99-107.

117. Landis WJ, Jacquet R. Association of calcium and phosphate ions with collagen in the mineralization of vertebrate tissues. Calcif Tissue Int. 2013;93:329-337.

118. Yang B, Cui FZ. Molecular modeling and mechanics studies on the initial stage of the collagen-mineralization process. Curr Appl Phys. 2007;7S1:e2-e5. 